DOI: https://doi.org/10.32870/

eees.v21i60.291
Omar Neme Castillo

Ana Lilia Valderrama Santibáñez*•

Álvaro Martín Vázquez Leyva*••

\section{Organizaciones de la Sociedad Civil y Objetivos de Desarrollo del Milenio: el caso del PCS}

En este trabajo se describe la contribución a los Objetivos de Desarrollo del Milenio (ODM) de las organizaciones de la sociedad civil apoyadas por el programa de coinversión social desde 2009 hasta 2012 a través de proyectos recurrentes. Se encuentra que este tipo de proyectos favorecen la focalización de esfuerzos, propiciando una mayor especialización y atención a problemas sociales, por lo que su contribución a los ODM es potencialmente alta.

Palabras clave: ODM, OSC, PCS, tercer sector, desarrollo social.

- Profesor-investigador de la Sección de Estudios de Posgrado e Investigación de la Escuela Superior de Economía del Instituto Politécnico Nacional

oneme@ipn.mx

- Profesora-investigadora de la Sección de Estudios de Posgrado e Investigación de la Escuela Superior de Economía del Instituto Politécnico Nacional

anavalderrama@ipn.mx

** Profesor de la Escuela Superior de Economía del Instituto Politécnico Nacional amartin_vazquez@live.com.mx
I. Introducción

En los últimos años, las organizaciones de la sociedad civil (OSC) han ganado espacios de expresión, colaboración y participación con organismos públicos, con otras OSC y con la comunidad en general, convirtiéndose en gestoras de atención de los problemas sociales. Con el surgimiento de estas se conformó el tercer sector, el cual, como concepto operativo, es reciente y sigue en construcción, dadas las distintas dimensiones que se le asocian (económica, social, antropológica, política y cultural), consideradas aspectos relativos a la naturaleza legal, económica o funcional de las propias organizaciones.

Las diferencias y dificultades en la definición del tercer sector han provocado que se carezca de elementos propicios para evaluar a nivel socioeconómico los impactos de sus acciones. Pero aun con estas diferencias se han hecho esfuerzos de medición; por ejemplo, la Organización de las Naciones Unidas (ONU) dispone del Manual sobre las Instituciones sin fines de lucro 
en el Sistema de Cuentas Nacionales, el cual, para estudiar el desarrollo de las organizaciones, las agrupa como sector, observa e identifica detalladamente las funciones que estas realizan y valora el trabajo voluntario de sus miembros.

El objetivo del presente trabajo es describir cómo las acciones de las OSC dependientes del Programa de Coinversión Social (PCS) han contribuido al desarrollo social de México y, particularmente, a los Objetivos de Desarrollo del Milenio (ODM). Para conseguirlo, se emplean estadísticas generadas a partir del padrón de beneficiarios del programa y a partir del reporte final que las OsC proporcionan al Instituto Nacional de Desarrollo Social (Indesol). Se sigue el método descriptivo tratando de identificar la contribución de los proyectos de las OSC en las metas planteadas en los ODM, principalmente en materia de salud, educación, pobreza y equidad de género. El análisis se limita a las organizaciones y proyectos apoyados por el PCS en todos los años del periodo 2009-2012. El supuesto es que este tipo de organizaciones cuentan con mayores capacidades de elaboración e implementación de proyectos, las cuales se traducen tanto en relaciones de continuidad como en una mayor capacidad de contribución a los ODM.

Así, de acuerdo con la ONU (Cumbre Mundial, 2010), alcanzar los objetivos del milenio -que abarcan la reducción de la pobreza, el hambre, la enfermedad y la exclusión- es un proceso que requiere de esfuerzos combinados, tanto del gobierno como del sector privado y de las organizaciones de la sociedad civil. Desde la visión positivista, las organizaciones civiles juegan un rol central en la divulgación e implementación de los ODM. La ONU señala que las OSC deben movilizar la opinión pública alrededor de los objetivos del milenio y alrededor de los compromisos de desarrollo de los países; proporcionar servicios de salud, educación, infraestructura para contribuir a alcanzar las metas; seguir 
las mejores prácticas, emplear la experiencia técnica y mantener comunicación con los gobiernos.

En este sentido, la literatura encuentra evidencia del papel favorable de las organizaciones de la sociedad en este proceso; por ejemplo, UNDP (2005), para el caso de Gambia, UNDP (2004), para un estudio de Asia, África y América Latina, y BID (2004) para América Latina. Sin embargo, la evidencia del impacto de estas organizaciones en los objetivos del milenio en México es limitada. Este documento contribuye en el área.

Además de esta introducción, el documento se compone de seis secciones. En la siguiente se describen el enfoque de desarrollo integral del ser humano. En la sección tres y cuatro se resumen los ODM y su nacionalización en el país, respectivamente. El marco en el que se desenvuelven los actores sociales se contextualiza en el apartado cinco. En la sexta sección se describe el impacto social de las acciones de las Osc. Por último, se presentan algunas reflexiones.

\section{Desarrollo social: algunas ideas teóricas}

Identificar el impacto en aspectos sociales de las acciones de las OSC requiere revisar el concepto desarrollo social para definir las posibles dimensiones de impacto. Una de las características del proceso de globalización ha sido la creciente complejidad en el estudio del desarrollo social y la pobreza, lo cual implica una dificultad para definir el impacto de diferentes acciones y programas a cargo del sector público o en manos de la sociedad civil organizada.

Para hablar de desarrollo social, un referente obligado es Amartya Sen, uno de los principales colaboradores del Programa de las Naciones Unidas para el Desarrollo (PNUD), en la conceptualización y medición del desarrollo. Una de las más importantes contribuciones de Sen (1997) en el desarrollo de los indicadores económicos y sociales 
Omar Neme Castillo, Ana Lilia Valderrama Santibáñez y Álvaro Martín Vázquez Leyva

es el concepto capacidad. Refiriéndose a los programas de gobierno, plantea que los objetivos de los programas deberían estar centrados en dotar de capacidades que permitan las condiciones para ejercer sus elecciones personales.

En su análisis conceptualiza a las personas sujetos de apoyo desde dos perspectivas: desde el bienestar y desde los actores; es decir, los considera activos en la solución de las situaciones que experimentan; lo que fundamenta el concepto desarrollo humano que ha ido evolucionando en el campo de la economía desde los años ochenta. El enfoque de las capacidades requiere diferenciar entre los conceptos libertad negativa y libertad positiva. Sen (1997) explica que la libertad negativa se centra en un concepto de libertad de elección entendido como no interferencia; mientras que la libertad positiva se entiende como la capacidad efectiva de una persona de ser o de hacer algo.

En ese sentido, Sen (1982) analiza cómo las mediciones tradicionales de la utilidad individual y social basadas en la cantidad de bienes proporcionan información sobre un aspecto de lo que el bien proporciona al ser humano, y no consideran realmente el bienestar completo del ser humano. Propone que un análisis más completo del efecto de los bienes y servicios sobre la utilidad requiere evaluar los bienes en función de sus características y de sus capacidades de generar bienestar al ser humano. De acuerdo con esto, las funciones y capacidades de los bienes deben considerarse para hablar de bienestar.

En línea con lo anterior, Sen (1985) explica que lo que crea bienestar no son los bienes como tales, sino las oportunidades funcionales y capacidades de desarrollo que genera su posesión. Señala que el desarrollo social requiere de un componente de justicia social, entendido como la igualdad de oportunidades. Plantea que es posible aplicar políticas sociales que mejoren el tradicional problema de distribución, y así reducir la pobreza sin que se vean incrementadas 
las capacidades productivas de un país. De este modo, las contribuciones de Sen llevan a diferenciar entre dos tipos posibles de indicadores para la evaluación: uno de resultados económicos y otro de capacidades productivas en los individuos y en las economías. Una forma de considerar los últimos es a través de la cobertura. Así, en la medida que los individuos tengan cubiertas ciertas necesidades, tendrán mayores capacidades productivas, lo que evidencia el potencial rol de las organizaciones de la sociedad civil para contribuir en el desarrollo social. Desde las ideas de Sen, a nivel internacional se considera que los principales objetivos del desarrollo social son mejorar las condiciones de vida de la población y proporcionarle los medios de participar plenamente en la esfera económica, política y social; naturaleza que se ve reflejada en los ODM y en proyectos de OSC.

Cabe mencionar que desde 1992 se asentaron las bases en la Cumbre Mundial sobre Desarrollo Social, hasta concretar la celebración de La Cumbre Mundial sobre Desarrollo Social en Copenhague (1995), la primera vez que los gobiernos se reunieron para discutir asuntos de desarrollo social. En la Cumbre, se llegó a un acuerdo con diez compromisos y el Programa de Acción de Copenhague. ${ }^{1}$ La Declaración de Copenhague reconoce a nivel mundial la importancia de la política social y coloca al ser humano en el centro de las preocupaciones de los gobiernos, en relación con el desarrollo sostenible. Además, ante la dificultad de establecer una forma internacional de evaluar los resulta-

I. De la Cumbre de Copenhague surgen diez compromisos: I) crear un entorno económico, político, social, cultural y jurídico, que permita el desarrollo social; 2) erradicar la pobreza en el mundo; 3) promover el pleno empleo; 4) promover la integración social; 5) lograr la igualdad y la equidad entre la mujer y el hombre; 6) acceso universal y equitativo a una educación de calidad y la atención primaria de la salud; 7) acelerar el desarrollo de África y de los países menos adelantados; 8) velar porque los programas de ajuste estructural incluyan objetivos de desarrollo social; 9) aumentar y utilizar con mayor eficacia los recursos para el desarrollo social; y 10) fortalecer la cooperación internacional, regional y subregional para el desarrollo social. 
dos del desarrollo social dadas las diferencias históricas, culturales y políticas de los países, la Cumbre identifica tres elementos del desarrollo social: pobreza, empleo pleno y productivo e integración social. ${ }^{2}$ Por último, se acuerda que en términos económicos y sociales, las políticas y las inversiones más productivas son las que facultan a las personas para aprovechar al máximo sus capacidades, recursos y oportunidades. En este orden de ideas, Midgley (1995: 1) afirma que el desarrollo social es "un proceso de promoción del bienestar de las personas vinculado a un proceso de desarrollo económico".

Para lograr una integración social se destacó el papel del gobierno en la promoción de una sociedad inclusiva; su papel para asegurar que las instituciones públicas respondan a las necesidades de toda la población y sean accesibles para todos; para fomentar la plena participación de la sociedad; para crear un marco jurídico y una estructura de apoyo que promueva el establecimiento de las organizaciones civiles y haga posible la participación de estas en la formulación, implementación y evaluación de políticas, programas y proyectos sociales.

Así, el elemento común en las definiciones aceptadas del desarrollo social es la importancia del aspecto subjetivo del bienestar y del enfoque de las capacidades individuales. Como se explicó, el concepto de enfoque de capacidades ha permitido el desarrollo de indicadores económicos y sociales que reflejan de mejor manera el concepto de desarrollo social. Para Sen (2000) el desarrollo humano se refiere a la creación de un entorno en el que las personas desplieguen su pleno potencial y tengan una vida productiva de acuerdo a sus intereses y necesidades. De todo lo anterior se desprende la existencia de elementos que complementan el concepto 
de desarrollo social, tales como los derechos humanos de primera generación (civiles y políticos), segunda (económicos, sociales y culturales) y tercera (paz y calidad de vida).

Para el caso concreto de México, el Plan Nacional de Desarrollo (PND) sectorial de Desarrollo Social y la Ley General de Desarrollo Social, señalan que la Secretaría de Desarrollo Social (SEDESOL) trabaja por un desarrollo social que tiene como principio rector el Desarrollo Humano Sustentable, concebido como el proceso permanente de ampliación de capacidades y libertades que permita a todos los mexicanos tener una vida digna sin comprometer el patrimonio de las generaciones futuras. Consiste en crear las condiciones para que todos los mexicanos tengan las mismas oportunidades. Como principios de desarrollo social en México se incluyen elementos como libertad -referida a la capacidad de elegir-, justicia distributiva -asociada con la equidad en la distribución de los beneficios-, solidaridad -respecto a la colaboración entre actores-, integralidad -que permite la articulación de cosmovisiones-, participación social -entendida como el derecho a la participación activa-, sustentabilidad -que implica la preservación del equilibrio ecológico-, respeto a la diversidad -es decir, no discriminación-, libre determinación y autonomía indígena, equidad de género -que permite reconocer las diferencias y tener los mismos derechos- y transparencia, la cual lleva a que la información de desarrollo social sea de dominio público.

\section{Contextualización del Tercer Sector}

Los conceptos tercer sector y sociedad civil se han utilizado en la literatura y en la política de manera indistinta, irreflexiva e indiscriminada, como una vía para integrar, clasificar y nombrar a los grupos emergentes de la sociedad. Siguiendo a Verduzco (2001), la variedad de aseveraciones del tema contribuyen a oscurecerlo aún más haciéndolo 
ambiguo. Esta problemática surge del hecho que ambos conceptos se refieren a aspectos tales como el derecho a asociarse y expresarse libremente, o bien a las políticas democráticas y a las garantías del Estado, entre otros. No obstante, para contextualizar y entender al tercer sector se tiene que partir de la noción sociedad civil. ${ }^{3}$

$\mathrm{Al}$ respecto, el término sociedad civil tiene un carácter polisémico y ambiguo que lo convierten en toda una categoría -excesivamente amplia y generalizada- que en un plano teórico, permite decir todo y nada al mismo tiempo, complejizando así su compresión (Sermeño, 2001). El Banco Mundial afirma que las definiciones de sociedad civil varían según los diversos paradigmas conceptuales, los orígenes históricos y los contextos nacionales en que esta emergió como un actor esencial para el desarrollo social.

A pesar de lo anterior, puede señalarse que la noción de sociedad civil se basa en la idea que existe una tercera esfera de la sociedad, junto al mercado y al Estado, caracterizada por la libre asociación e interacción social que determina la democratización a partir del fortalecimiento de los actores sociales y de su control progresivo sobre las otras dos esferas (Thayer y Elizalde, 2011). Siguiendo con el planteamiento de Thayer y Elizalde (2011), la sociedad civil se compone de dos conjuntos esenciales: instituciones sociales y movimientos sociales. Los primeros definen los derechos individuales, políticos y sociales que permiten una libre asociatividad, la defensa contra el Estado y el mercado, y la oportunidad de la participación ciudadana en asuntos públicos. Los segundos plantean sistemáticamente nuevos principios, valores y demandas sociales.

En síntesis, la sociedad civil es la suma de todas las organizaciones y redes que se ubican fuera del aparato 
estatal formal. ${ }^{4}$ Incluye, en palabras de Olvera (1998), organizaciones entendidas como asociaciones de ciudadanos que haciendo uso de recursos simbólicos y materiales, capacidades organizacionales y afinidades emotivas y morales actúan colectivamente a favor de alguna causa y persiguen algún interés material o simbólico situándose por fuera del sistema político y sin seguir la lógica del mercado. Para el Banco Mundial, la sociedad civil hace referencia a una amplia esfera de organizaciones no gubernamentales y sin fines de lucro presentes en la vida pública, las cuales expresan los intereses y valores de sus miembros y de otros siguiendo consideraciones éticas, culturales, políticas, científicas, religiosas o filantrópicas.

Respecto a la definición del concepto de tercer sector, la problemática es similar. Rodríguez (2005) afirma que el uso de este concepto ha llevado a confusiones debido a las diversas interpretaciones y a la imprecisión de las nociones empleadas. Se utiliza indistintamente como sinónimo de categorías tales como sociedad civil, organizaciones no gubernamentales, voluntarias o no lucrativas. El Centro para la Sociedad Civil hace referencia al tercer sector como el espacio de la acción colectiva sin coacción en torno a intereses, propósitos y valores compartidos. Añade que abarca una diversidad de espacios, actores y formas institucionales, que varían en su grado de formalidad, autonomía y poder. De acuerdo con Rodríguez (2005), el tercer sector es potenciado desde las instituciones sociales que designan las variadas formas organizativas que surgen de la sociedad, identificadas por la promoción de la cooperación social y del trabajo voluntario, bajo una lógica altruista y solidaria.

Así, una de las fuentes de imprecisión de dicha noción está en la perspectiva con que se le mira. Desde el enfoque

4. Para Olvera (1998) la idea de sociedad civil en México se ha usado como un medio para diferenciar a la sociedad del Estado. 
estructuralista este sector se compone de organizaciones que no son públicas ni mercantiles. La denominación tercer sector se utiliza para diferenciar las organizaciones sociales respecto de los otros dos "ámbitos": el Estado y el mercado, por lo que se define residualmente. Al respecto, Salamon y Anheir (1994) argumentan que este sector está fuera del mercado (no persigue el lucro) y también del gobierno (no busca el control).

Para la perspectiva voluntarista, el sector es sinónimo de trabajo voluntario. El enfoque legal lo considera como un conjunto de atribuciones, derechos y deberes, con normas y reglas específicas, mediante las cuales los actores sociales adquieren su estatus legal. Desde el punto de vista económico, el tercer sector se integra solo por organizaciones con recursos obtenidos a partir de donativos privados y subsidios. Por último, la perspectiva política tiende a identificarlo con el propio concepto de sociedad civil, donde las organizaciones tienen poder de decisión, acción y voluntad propia.

No obstante, un elemento común entre el tercer sector y la sociedad civil es su separación de los sectores mercantil y gubernamental. Por tanto, el vínculo entre estos conceptos es que ambos realizan actividades libres y autónomas con un propósito social. Más allá de la distinción entre ambas, las organizaciones comprendidas por estos conceptos se caracterizan por ser no lucrativas y por seguir un rol de productoras de servicios sociales tendientes a complementar las funciones sociales del Estado. Por ende, en este documento el término tercer sector hace referencia de forma genérica a las organizaciones de la sociedad civil.

El problema de la indefinición conceptual se manifiesta aún más al momento de su operacionalización en la forma de indicadores para medir el impacto de las acciones de las organizaciones civiles empleando diferentes metodologías de evaluación; situación que condiciona los resultados de la evaluación abriendo todo un abanico de debates y polémicas 
respecto de su validez y de los supuestos teóricos desde los que han partido. Aun así, se puede decir que las OSC son los actores de ese tercer sector compuesto por entidades creadas por los mismos miembros de la sociedad, que llevan a cabo funciones que el gobierno o bien no realiza o bien realiza limitadamente. De acuerdo con el Indesol, los actores sociales son "organizaciones de la Sociedad Civil e Instituciones de Educación Superior y Centro de Investigación que participan en el PCS mediante proyectos de coinversión”.

Brevemente, los criterios establecidos por Salamon y Anheier (1997) permiten caracterizar a los actores del tercer sector (TS), los cuales son: $i$ ) organizaciones formales, con presencia y estructura institucional, con mecanismos legales que regulan el ingreso, permanencia, promoción y exclusión de sus miembros y sus relaciones; que cuentan con espacio físico y manuales de procedimiento, planes formales, etc.; $i$ ) organizaciones privadas independientes del gobierno y sus funcionarios y de las entidades privadas, pero con posibilidades de recibir recursos de estos; iii) organizaciones basadas en el principio de "utilidad social", por lo que los beneficios obtenidos son reinvertidos; $i v$ ) organizaciones autónomas, las cuales controlan sus actividades, cuentan con un grado de independencia y equipamiento que les permite decidir sus actividades; y $v$ ) organizaciones integradas por participación voluntaria, lo que no implica que sus ingresos provengan de los voluntarios.

Asimismo y de acuerdo con Najam (1999), las actividades desempeñadas por las OSC se engloban en cinco roles: i) supervisor: monitoreando que las acciones, apoyos y recursos comprometidos se ejecuten de la forma señalada; ii) abogado: presionando directamente para que las alternativas de su interés se cumplan; iii) innovador: desarrollando y señalando nuevas formas de diseño e implementación de programas y acciones; $i v$ ) proveedor de servicios: actuando directamente para satisfacer una necesidad de servicios, 
especialmente a grupos marginados y vulnerables, y $v$ ) constructor de capacidades: ofreciendo apoyo a las comunidades o a otras OSC. En este sentido, las OSC crean valor público o tienen fines de utilidad social, puesto que sus acciones permiten satisfacer ciertas demandas sociales generando un bienestar en la población que atienden. De esta forma, es claro que en su conformación y desarrollo surgen externalidades positivas que el Estado busca fomentar mediante políticas de apoyo. Así, los proyectos y acciones concretas de tales organizaciones, en cualquiera de las áreas en las que se desenvuelven, resultan estratégicas para el fortalecimiento del tejido social y del capital social, las bases del desarrollo social.

Desde un punto de vista teórico, los elementos que permiten que las organizaciones de la sociedad contribuyan al desarrollo social son: $i$ ) escala, $i$ ) habilidad para alcanzar a poblaciones pobres, iii) capacidad para innovar, $i v$ ) representatividad y permanencia, $v$ ) trato personalizado, y vi) complementariedad de recursos (Clark, 1997). Sus características les permiten mayor presencia y aceptación social y, de esta manera, impacto en el desarrollo social y en los niveles de pobreza, pues tienen mayor claridad de la situación particular de la población que atienden. Al estar más cercanas a la comunidad es más factible que encuentren y construyan, combinando recursos con la comunidad, soluciones innovadoras. Finalmente, al participar la población con la organización logran legitimar su representatividad y permanencia.

También, para potenciar las acciones de las OsC se deben redefinir las relaciones entre estas organizaciones y los gobiernos, principalmente los municipales, equilibrando la responsabilidad, participación, implementación, diálogo, seguimiento y rendición de cuentas. De acuerdo con la CEPAL (2013), se requiere una combinación de una sociedad civil más activa y comprometida, capaz de expresar las deman- 
das de la ciudadanía, con un Estado más efectivo, con mayor capacidad de respuesta, que entregue los servicios públicos necesarios. Por ende, el grado de compromiso, de recursos financieros y de capital social de las Osc determinan las asimetrías en los procesos de intervención y su impacto en el desarrollo social.

Siguiendo este orden de ideas, es pertinente considerar dos aspectos esenciales para el desarrollo social, los cuales están ligados a la presencia de las organizaciones sociales. Así es que para la teoría contemporánea el capital social está en las normas y en las relaciones sociales de los grupos y las comunidades, con lo cual es posible alcanzar objetivos comunes (Putnam, 1995); mientras para Coleman (1997) este se forma de distintas entidades interdependientes pero similares en dos elementos: el primero es que ambas surgen de la estructura social; el segundo es que ambas facilitan las acciones sociales dentro de esa estructura. De acuerdo con Häuberer (2011) el capital social puede definirse como los recursos contenidos en las redes sociales que son accesibles a sus miembros o actores; lo que implica recursos contenidos en las relaciones sociales, pero no en las personas, y acceso de los actores sociales a tales recursos. Coleman (1997) señala un aspecto clave del capital social: que este es productivo porque hace posible el logro de ciertos fines que sin él sería imposible.

La premisa central del concepto capital social es que las redes sociales tienen valor. Tal concepto se refiere al valor colectivo de dichas redes -es decir, las personas que conoce un individuo, la frecuencia con que las procura, el tipo de relaciones que establece con ellas, etc.- y a las dinámicas que surgen respecto a las normas de reciprocidad, confianza y apoyo emocional. Los beneficios potenciales de este capital pueden verse a partir de los vínculos sociales: amigos y familiares pueden ayudarse en distintas formas (emocional, social y económica); por lo que un mayor capital social que 
lleve a una mayor interacción social se reflejará en beneficios individuales tangibles (préstamos, empleo, acceso a información, etc.) que, además, pueden transmitirse al grupo de pertenencia. ${ }^{5}$

Como resulta obvio, el concepto de capital social ha sido criticado desde diferentes enfoques. En particular, el compromiso social en el que se basa este capital evoluciona y no se erosiona, como argumenta Putnam (2003). Así, en lugar que las personas se unan fuertemente a grupos en sus colonias, se vinculan a grupos de personas que comparten creencias más allá de la localidad. De acuerdo con Keeley (2007), el término capital social es vago, difícil de medir, y quizás no sea una forma de capital en absoluto. ${ }^{6}$ Coleman (1997) sugiere que en el capital social existen aspectos excluyentes; por ejemplo, comunidades muy pequeñas y cerradas pueden tener actitudes hostiles al cambio, desterrando así individuos de esa red social.

A pesar del debate, el capital social es un concepto atractivo desde el punto de vista político, social y económico; consecuencia de la creciente preocupación por la marginación en las sociedades y de la necesidad inherente de actuar para combatir este tipo de problemas. En este sentido, la noción ciudadanía ha ganado terreno como un proceso para propiciar el desarrollo económico de los Estados nacionales. Sobre este punto, Espadas (2006) afirma que para explicar el concepto de ciudadanía, es necesario partir de las ideas de Marshall (1998), quien distingue tres tipos de ciuda-

5.Vinculado a esto, el capital social comprende habilidades, redes y capital cultural. Los dos primeros permiten a un individuo obtener beneficios, de mercado o no, de la interacción social con otros, que no se miden necesariamente en términos económicos.

6. Keeley (2007) considera que, desde el punto de vista económico, el capital comprende la realización de algún sacrificio hoy a cambio de ganancias en el futuro. No obstante, dadas las normas de reciprocidad en el capital social, un individuo puede sacrificarse hoy a favor de un miembro de la red, esperando que en el futuro se "devuelva" el favor. 
danía: civil, política y social. El primero corresponde a las libertades individuales, de expresión, de pensamientos y a la propiedad privada. El segundo se refiere a los derechos a ejercer el poder político, directo o indirecto. Y la ciudadanía social implica garantías de seguridad y bienestar económico (educación, salud, servicios sociales y empleo), las cuales son proporcionadas por el Estado.

En general, la ciudadanía se explica desde dos categorías (Morgan, 2008). Por un lado, se entiende la participación individual en asuntos cívicos o públicos, como una consecuencia de la elección que se determina a través de la evaluación racional de costos y beneficios marginales de esa participación, partiendo del marco de referencia individual -normas y creencias- de los derechos y obligaciones de la ciudadanía. Por otro lado, la participación ciudadana es vista como una consecuencia de la estructura dominante de la sociedad. Aquí, los miembros individuales de una sociedad, socializan por medio de las normas, los valores y los comportamientos de los grupos sociales a los que pertenecen y a otros de la sociedad en general. Por lo tanto, este tipo de participación puede explicarse desde la lógica del capital social.

En este contexto, la literatura aboga por una mayor responsabilidad de ciudadanos y sociedad civil como agentes de bienestar en un marco en el que el individuo actúa en un espacio colectivo más amplio. El papel protagónico surge del comportamiento activo del individuo (Espadas, 2006), lo cual lleva al concepto ciudadanía activa, el cual supone una actividad crítica y responsable del compromiso político. Así las cosas, la participación ciudadana es importante, porque establece el sentido de pertenencia permitiendo la sostenibilidad de las iniciativas de desarrollo, dando voz a los pobres y marginados, y vinculado la estrategia de desarrollo a las necesidades de las personas (Narayan y Shah, 2000).

Para Alonso (1999) la ciudadanía activa supone el establecimiento de relaciones de confianza y responsabilidades 
compartidas para la obtención de beneficios mutuos y colectivos. ${ }^{7}$ El concepto ciudadanía, por ende, se refiere a la construcción de una identidad común que involucra a los ciudadanos en la defensa y ampliación de valores y derechos. En este orden de ideas, el capital social se construye sobre la participación ciudadana, es decir, sobre redes sociales sin estructuras jerárquicas formales, conformadas por actores agrupados para incidir en asuntos públicos (Bresser y Cunill, 1998). Como la ciudadanía es inclusiva, la apertura de la estructura social del grupo de pertenencia representa un juego de suma positiva. De modo que a mayor capital social, mayor participación ciudadana. Ortega et ál. (2000) argumentan que la relación entre capital social y ciudadanía se basa en tres dimensiones: aspiraciones individuales a un orden colectivo; vínculo social, asociado al propio capital social; y ciudadanía, donde se manifiestan las condiciones institucionales y cívicas que hacen posible que esas aspiraciones se hagan realidad.

\section{ODM: Algunas consideraciones para las OSC}

Los ODM tienen sus orígenes en diversas reuniones internacionales y conferencias globales de las Naciones Unidas, celebradas principalmente en los noventas. Desde su aprobación por la Asamblea General de las Naciones Unidas en el 2000, los objetivos y metas han impulsado nuevas estrategias y visiones relativas al desarrollo mundial. La búsqueda de esas metas en el corto plazo representa la oportunidad histórica de arraigar a las políticas sociales y económicas en el quehacer de cualquier nivel de gobierno,

7. En consecuencia, las sociedades con altos índices de confianza y de capital social, tienen más probabilidades de disfrutar un buen gobierno, seguridad, paz, riqueza y éxito, dado que las personas amplían sus redes con confianza y niveles de participación (Pennant, 2005). 
del sector privado y de la sociedad civil organizada, dotando de un carácter más endógeno al proceso de desarrollo.

En la Declaración del Milenio se definen objetivos específicos, así como metas claras y mensurables, lo cual es compartido por un grupo de países. Cada uno de los ODM es reconocido por la Asamblea y son parte esencial de la implementación de la Declaración del Milenio. ${ }^{8}$ Concretamente, los ODM globales son: i) erradicar la pobreza extrema y el hambre; ii) lograr la enseñanza primaria universal; iii) promover la igualdad de género y el empoderamiento de la mujer; $i v$ ) reducir la mortalidad de los niños menores de cinco años; $v$ ) mejorar la salud materna; vi) combatir el VIH/Sida, el paludismo y otras enfermedades; vii) garantizar la sostenibilidad del medio ambiente; viii) fomentar una alianza mundial para el desarrollo. ${ }^{9}$

Empero, existe una discusión respecto a las bondades de su implementación. Las opiniones se dividen entre las que revelan un claro apoyo hacia los objetivos y las que los rechazan en su totalidad, centrándose en aspectos como la eficacia de su planeación o el ajuste de los objetivos cuantitativos. Referente a esto, quienes celebran los éxitos de los objetivos señalan que su implementación ha llevado a la movilización del apoyo global, público y político para el desarrollo. Moss (2010) argumenta que en el caso de los países donantes esto se refleja en el aumento de los compromisos de ayuda, en el número de campañas que abogan por reformas comerciales a nivel mundial, en las mejoras en las condiciones de las deudas nacionales y en la ayuda internacional; todo lo cual es el marco de la actividad política en torno a la cooperación internacional. Jahan (2010), por su parte, asevera que los ODM se han convertido en una poderosa herramienta para el desarrollo en términos

8. http://www.undp.org/content/undp/en/home/mdgoverview/

9. Para mayor información puede consultarse: http://www.un.org/millenniumgoals/ 
políticos y de respaldo popular, lo cual es consecuencia de su diseño claro y conciso, que equilibra la complejidad del proceso de desarrollo. Por consiguiente, dado los acuerdos globales, se entienden los objetivos del milenio como un catalizador del cambio social y económico. ${ }^{10}$

En general, una ventaja de los objetivos, si bien supeditada a la cooperación internacional, es que se han centrado en medidas más amplias de desarrollo humano, en contraposición al crecimiento económico, porque incorporan un enfoque más integral. Sin embargo, distintas críticas afirman que esta ideología se sesga hacia aspectos materiales, obviando elementos cualitativos, considerando que los ODM se concentran en el crecimiento económico, en la conformación de un mercado global libre y en la extrema privatización (Amin, 2006).

Para Khoo (2005) los más escépticos aseveran que estos objetivos son irrelevantes e incluso destinados al fracaso, lo cual se explica porque han sido fijados desde arriba para ser aplicados abajo; situación que implica, además, un sesgo a favor de los países donantes. Esto representa el riesgo de reproducción de pautas del pasado, puesto que los objetivos, diseñados por los países donantes, condicionan a los países receptores al establecimiento de políticas de ajuste estructural similares a las de la segunda mitad del siglo pasado. Para Sumner (2009) los ODM siguen una agenda definida por las realidades de los donantes; misma que no considera la heterogeneidad local y que castiga a los países cuando incumplen sus metas.

Así pues, se denuncia el carácter arbitrario de los objetivos cuantitativos, puesto que se preocupan más por alcanzar un valor dado que por los aspectos cualitativos. Como señala Jolly (2003), "si los ODM se centran demasiado en 
el objetivo de reducir a la mitad el hambre para el 2015, puede perderse de vista el hecho de que el objetivo es el de eliminar el hambre y no reducirla a la mitad". Cabe preguntarse ¿qué pasa con las personas que no fueron beneficiadas con las acciones para reducir a la mitad el hambre? Otros argumentos apuntan a que la estructura actual de los objetivos presenta el peor escenario posible para que se alcancen las metas para los que fueron diseñados; por lo cual Deepak (2011), al hablar de las "dimensiones faltantes", apunta que la crítica es precisamente por lo que se omite, pues las metas no ponen suficiente énfasis en aspectos como el desarrollo sostenible; además, se resumen en una interpretación reduccionista de los criterios de la Declaración del Milenio, dejándose de lado cuestiones como la paz, la seguridad, la reforma de instituciones para la gobernabilidad democrática mundial, el cambio climático, la calidad de la educación y la infraestructura, entre otros (Vandemoortele y Delamonica, 2010).

En el caso de América Latina, se señala que los ODM no incorporaron elementos clave, como la defensa de los derechos sexuales y reproductivos y el empoderamiento de las mujeres, o la erradicación de la violencia contra mujeres y niñas; todo, bajo una perspectiva de igualdad de género. De hecho, Holmes y Jones (2010) sostienen que únicamente dos objetivos consideran medidas desagregadas por género, y que no hacer frente a estas cuestiones lleva intrínseco el riesgo de que la naturaleza de los problemas de la pobreza no se comprenda correctamente; incomprensión que se convierte en un obstáculo para las metas del milenio.

De igual forma y de acuerdo con la ONU, los objetivos fallan al no considerar aspectos como la igualdad, la protección social y la responsabilidad de rendir cuentas, atender a los grupos más vulnerables y combatir las injusticias sistemáticas. Para algunos críticos, los objetivos tienen -por su diseño- alcances limitados, dado que descuidan a los más 
Omar Neme Castillo, Ana Lilia Valderrama Santibáñez y Álvaro Martín Vázquez Leyva

pobres y vulnerables. Según Hulme (2010), los objetivos se basan en progresos promedio a nivel nacional o global, por lo que en su medición algunas personas estarán por debajo de ese nivel. El autor agrega que en algunos países el avance de las metas parece impresionante, pero la situación ha empeorado para los más pobres y vulnerables. Por ende, los ODM han dejado a más de 1000 millones de personas en el hambre y la pobreza, a través de un proceso en el que algunos se benefician a costa de otros, creándose así un círculo perverso, donde la desigualdad aumenta y limita el cumplimiento de los objetivos.

Recapitulando, tras considerar los aspectos positivos y negativos de los ODM, parece no existir una respuesta que aclare si realmente son eficaces como agentes procuradores del desarrollo. No obstante, como señala Vandemoortele (2009), las discusiones post-2015 representan una clara oportunidad para responder a las críticas sobre los objetivos y su reformulación. Al final, una ventaja de los indicadores ODM es que facilitan la observación tanto del estado actual como del progreso obtenido, lo cual permite que se redefinan las estrategias necesarias o se profundice en su definición. En este contexto, para el desarrollo social sostenido se requiere de la participación activa de la sociedad civil, a tal grado que se establezcan proyectos que respalden estas iniciativas. Así lo sugiere Shepherd (2008). Desde este enfoque, las organizaciones de la sociedad son corresponsables de implementar acciones y destinar recursos para en el ámbito social.

\section{Nacionalización de ODM en México}

Dadas las críticas a los ODM porque su diseño no considera los contextos locales, se argumenta que las metas deben atendiendo las circunstancias nacionales, lo cual implicaría tratar a los países de forma diferenciada y, en 
última instancia, incluir un ajuste conforme al PIB nacional de cada uno (Langford, 2010). En consecuencia, una forma que permitiría dinamizar las acciones de los actores involucrados hacia la consecución de los ODM es el proceso de nacionalización, que básicamente ajusta los ocho objetivos internacionales a las condiciones actuales de cada economía. Para ello, las metas deben ajustarse a las prioridades y recursos nacionales; que ciertas metas globales se modifiquen para reflejar la situación real de cada país.

En opinión de Canudas (2012) el proceso de nacionalización -que permitiría que los agentes involucrados se apropiaran de los ODM y, consecuentemente, de sus acciones- debe cumplir con ciertas características; a saber: $i$ ) desagregación de objetivos, metas e indicadores a nivel adecuado (consideración de las condiciones del desarrollo de cada país y región: realistas y ambiciosas, pertinentes socialmente, consistentes con objetivos gubernamentales de largo plazo; ii) movilización de recursos basado en prioridades y una distribución más equitativa tanto a nivel nacional como internacional; iii) reforzamiento de las capacidades técnicas y gerenciales, orientadas hacia la gerencia basada en la evidencia, lo que permitiría aumentar la efectividad de las políticas públicas y, particularmente, de los proyectos sociales financiados; e iv) implementación de sistemas de seguimiento y evaluación, para establecer medidas correctivas oportunas en las acciones realizadas por los actores sociales.

Asimismo, Canudas (2012) señala que la efectividad de la nacionalización es mayor cuando se realiza en el marco de una estrategia nacional de desarrollo de largo plazo que lleva a integrar los objetivos en una estrategia de mediano plazo. Agrega que una condición para la operacionalización es su transversalidad en los planes nacionales de desarrollo, los que incorporan objetivos, metas, indicadores y estrategias prioritarios para cada sociedad a nivel nacional 
y sectorial. Por ende, conforme los ODM -ajustados- se consideren en estos, las oportunidades de alcanzar etapas más avanzadas en el desarrollo se potencian, gracias al impulso de la rendición de cuentas y el seguimiento de los avances.

En el caso mexicano, una estrategia central en el combate de la pobreza es la mejora de las condiciones físicas y sociales dentro del eje de la política social. ${ }^{11}$ El gobierno de Calderón se basó en diferentes programas orientados a mejorar este entorno; particularmente el PCS que promueve la ejecución de proyectos de cofinanciamiento entre el gobierno y las OSC para apoyar a grupos vulnerables, impulsando acciones de desarrollo social humano y sustentable, acciones de promoción de los derechos económicos, sociales y culturales, y acciones de equidad de género, así como la generación de conocimiento y metodologías de utilidad para la política pública; ${ }^{12}$ dimensiones que en su mayoría son consideradas desde la Declaración de Copenhague.

También para el caso de México se presenta una "nacionalización" de estos ODM y, en consecuencia, se incluyen tres metas adicionales conocidas como Metas Más Allá del Milenio (MMM). Estas son: reducir a la mitad la proporción de personas en pobreza alimentaria entre 1990 y 2015 , asegurar que para 2015 todos los niños entre los tres y cinco años de edad reciban educación preescolar y la concluyan en el tiempo normativo (tres años), y asegurar que para 2015 todos los jóvenes de 12 años de edad ingresen a la enseñanza secundaria, que la cohorte entre 12 y 14 años

I I. La política social busca el fomento del desarrollo social y humano estructurada en cuatro ejes: i) desarrollo de capacidades básicas, ii) consolidación de una red de protección social, iii) establecimiento de vínculos entre las oportunidades de desarrollo económico y las de desarrollo social, y iv) desarrollo y mejoramiento del entorno físico y social a nivel familiar y comunitario.

12. Adicionalmente, se pusieron en marcha los programas: i) Tu Casa y Vivienda Rural; y ii) Programa para el Desarrollo de Zonas Prioritarias, con la creación o mejora de infraestructura social básica y de servicios, que contribuye a reducir desigualdades regionales. 
reciba la enseñanza secundaria y que el 90 por ciento de esta la concluya en el tiempo normativo (tres años).

Ahí mismo se tomaron en cuenta los siguientes indicadores asociados: proporción de la población que habita en hogares en pobreza alimentaria; proporción de la población urbana que habita en hogares en pobreza alimentaria; proporción de la población rural que habita en hogares en pobreza alimentaria; porcentaje de asistencia escolar (6 a 11 años de edad); tasa neta de matriculación en secundaria (12 a 14 años); tasa neta de nuevo ingreso a secundaria (12 años); tasa de absorción de los egresados de primaria; eficiencia terminal en secundaria; porcentaje de asistencia escolar (12 a 14 años); tasa de mortalidad en niños menores de 5 años por enfermedades diarreicas (defunciones por cada 100000 menores de 5 años); tasa de mortalidad en niños menores de 5 años por enfermedades respiratorias agudas (defunciones por cada 100000 menores de 5 años); porcentaje de adultos y niños con VIH que continúan con el tratamiento 12 meses después de empezar la terapia antirretroviral; y proporción de la superficie bajo manejo sustentable. Con todo, en este documento solo se consideran los ODM generales. Una extensión del este artículo va en esta dirección.

Por último, atendiendo la lectura de Canudas (2012), la adaptación de los ODM a la situación nacional resulta esencial para su apropiación por los actores involucrados, la cual se reflejaría en un mayor apoyo de las acciones orientadas a su logro. Simultáneamente, los actores, agrupados en los tres sectores deben incidir de forma coordinada con sus acciones en este proceso de apropiación. En ese sentido, las organizaciones sociales se convierten en un actor clave y deben colocar en el núcleo de sus proyectos intervenciones alineadas a los objetivos nacionalizados, considerando siempre los vínculos entre resultados en materia de salud, educación y desarrollo productivo. 
En adición y dado que los objetivos del milenio se sustentan filosóficamente en los derechos humanos, su cumplimiento debe guiar la asignación de recursos públicos y, consecuentemente, las acciones y proyectos de las organizaciones civiles, por lo que estos deben centrarse en los ámbitos considerados en los primeros siete objetivos. Siguiendo este enfoque, con la integración de los ODM en el Plan Nacional de Desarrollo y la alineación de los proyectos PCS, se ha de establecer una plataforma más sólida para el desarrollo humano al dotar de capacidades a los individuos en las sociedades para ejercer sus elecciones personales.

\section{Impacto de los actores sociales: el caso de los ODM}

¿Cuál es la contribución de las OsC a la consecución de los Objetivos de Desarrollo del Milenio en México? La metodología de análisis considera primero la base de organizaciones beneficiarias del PCS de 2009 a 2012, con el objetivo de identificar tanto las organizaciones como los proyectos recurrentes (OSC con al menos un proyecto cada año y proyectos que se implementan al menos dos años). Doscientas treinta y cinco organizaciones cumplen con esta característica. El análisis se centra en una muestra aleatoria, con error del 5\%, nivel de confianza del $95 \%$ y probabilidad de ocurrencia entre $5 \%$ y $95 \%$, lo que incluye 141 organizaciones. Además, partiendo de la base de datos de beneficiarios del PCS, se agruparon los proyectos y OSC de acuerdo con la Clasificación Internacional de Organizaciones Sin Fines de Lucro (CIOSFL), para determinar regularidades en los proyectos y en las organizaciones recurrentes. También se consideraron los reportes finales al programa para identificar los objetivos, orientación y temas de los proyectos presentados; esto fue para homologarlos con los objetivos del milenio (véase el cuadro 1). Dado que cada objetivo se asocia con un número de metas e indicadores, se considera 
el efecto relacionando los indicadores de los objetivos y las acciones apoyadas mediante coinversión.

De acuerdo con el BID (2004) el logro de los objetivos requiere que las OSC: $i$ ) promuevan los ODM como marco de referencia e instrumento para la erradicación de la pobreza, garantizando su apropiación en los países; ii) aseguren mediante la definición de mecanismos de consulta y de pautas de referencia la participación efectiva de los pobres y excluidos en el proceso de implementación y seguimiento de los objetivos; iii) se involucren en el monitoreo, acompañamiento y evaluación; iv) desarrollen asociaciones para valorizar los sistemas e instituciones democráticas dedicadas a la reducción de pobreza y la inclusión social. El objeto social de las OSC se relaciona, en principio, con los primeros siete objetivos del Milenio. ${ }^{13}$ Esto sugiere que estas organizaciones tienen potencial para contribuir desde sus respectivos campos al alcance de los objetivos. Así, el PCS, mediante el apoyo de diferentes tipos de proyectos, se convierte en una pieza clave para avanzar en las metas.

El cuadro 1 presenta los objetivos, metas e indicadores del milenio para México relacionados con la CIOSFL, de acuerdo con la homologación realizada. Se registran datos para cinco años. Se aprecia un avance considerable hacia el cumplimiento de los objetivos en todas las dimensiones. Prácticamente todos los indicadores muestran progreso, con la excepción del índice de paridad entre géneros en la enseñanza terciaria y el porcentaje de la población entre 15 y 49 años con VIH, los cuales se movieron ligeramente en dirección contraria a la esperada durante el último año. Asimismo, el porcentaje de población desnutrida se ha

13. Para ello, los ODM se agrupan en cuatro categorías:i) erradicación de pobreza y hambre; enseñanza primaria universal; iii) igualdad de género y empoderamiento de la mujer;y iv) reducir la mortalidad de los niños menores de cinco años; mejorar la salud materna; combatir el VIH/Sida; que se homologan con la CIOSFL de acuerdo a las categorías: i) desarrollo y vivienda; ii) educación e investigación; iii) derecho, promoción y política; y iv) salud, respectivamente. 
Omar Neme Castillo, Ana Lilia Valderrama Santibáñez y Álvaro Martín Vázquez Leyva

mantenido constante en los últimos diez años. Los mayores logros se registran en la meta asociada a la reducción de la mortalidad en niños de cinco años; particularmente, en la reducción de las tasas de mortalidad de niños menores a cinco años y de mortalidad infantil (entre ninguno y un año de vida) por cada 1000 nacidos vivos.

Cabe señalar que la mayor fuerza de los ODM está precisamente en su carácter específico respecto a los logros enmarcados temporalmente (Canudas, 2012). Lo anterior significa que es posible dar seguimiento a la probabilidad de que los objetivos y metas puedan lograrse. Así, en el cuadro 1 también se muestra el estado de los indicadores al 2012 , los avances y las metas establecidas para $2015 .{ }^{14}$ En general, se aprecia una evolución favorable en los indicadores seleccionados. Cuatro metas se alcanzaron ya, relacionadas con la igualdad de género, acceso al agua potable y el logro de una enseñanza primaria universal. Solo tres metas están en riesgo de incumplimiento, principalmente las relacionadas con los aspectos económicos y la salud: la tasa de crecimiento del PIB por persona empleada, la razón empleo-población y la mortalidad materna.

Pero ¿son alcanzables las metas del Milenio en México? En cuanto a la erradicación de la pobreza y el hambre, la CEPAL (2005) estima que para reducir a la mitad la pobreza de los países latinoamericanos de ingreso medio estos deberían crecer $4.4 \%$ anual de 2004 a 2015 . Como referencia, la tasa de crecimiento promedio anual del PIB real es de $2.02 \%$, lo cual muestra un déficit en la tasa de crecimiento de 2.18 puntos porcentuales. Esta situación refleja la difi- 
cultad que enfrenta el Estado mexicano para cumplir con este objetivo. ${ }^{15}$

Además, según la cuenta pública en 2012 el presupuesto destinado al desarrollo social, si bien concentra $11.8 \%$ del PIB (58.2 \% de los recursos para este tipo de erogaciones), ${ }^{16}$ evidencia la restricción de los recursos para el desarrollo social y en especial para el combate de la pobreza toda vez que considera que existen cerca de cincuenta y dos millones de pobres. Si el total del presupuesto para el desarrollo social se hubiera destinado al combate de la pobreza, cada persona en esta condición habría recibido, en promedio, 33000 pesos en todo el año; cantidad muy limitada para contribuir a la meta.

Por último, como una manera de dimensionar la contribución de las OSC a los objetivos del milenio, en el cuadro 2 se resumen los principales apoyos económicos federales a estas organizaciones en 2012. El total del financiamiento fue de 5900 millones de pesos, dividido en nueve secretarías, lo que representa un $0.6 \%$ del total del gasto en desarrollo social. El apoyo económico promedio es de 247000 pesos. Para el caso del Indesol, este monto es menor, solo por arriba de dos entidades.

Desde esta perspectiva, parece que el potencial de las OSC para contribuir directamente en los objetivos del milenio está limitado, por lo que la generación de desarrollo social autónomo depende fuertemente de un verdadero compromiso estatal para hacer llegar recursos económicos a estas organizaciones de la sociedad. No obstante, dado que las

15. Atisophon et ál. (20II) argumentan que una estrategia de los países en desarrollo es mejorar la recaudación de impuestos y la ampliación de la base fiscal como una forma de financiar los objetivos.

16. En el presupuesto asignado al desarrollo social se incluyen rubros asociados con la protección ambiental, vivienda, salud, recreación y cultura, educación, protección social y otros; todos aspectos vinculados tanto con los ODM como con los proyectos del Programa de Coinversión Social al que acceden las organizaciones de la sociedad civil. 
Omar Neme Castillo, Ana Lilia Valderrama Santibáñez y Álvaro Martín Vázquez Leyva

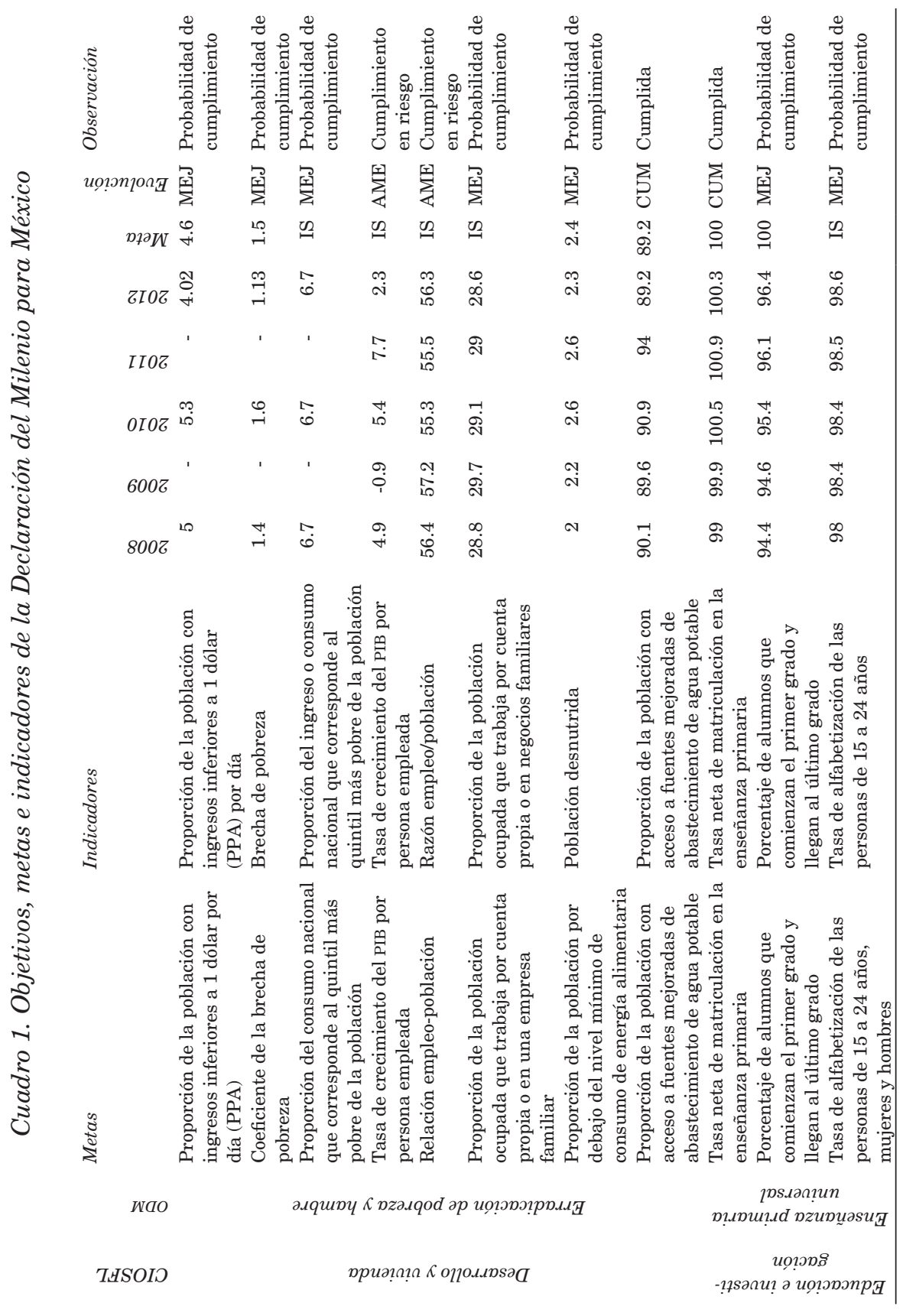

158 
Organizaciones de la Sociedad Civil y Objetivos de Desarrollo del Milenio:

el caso del PCS

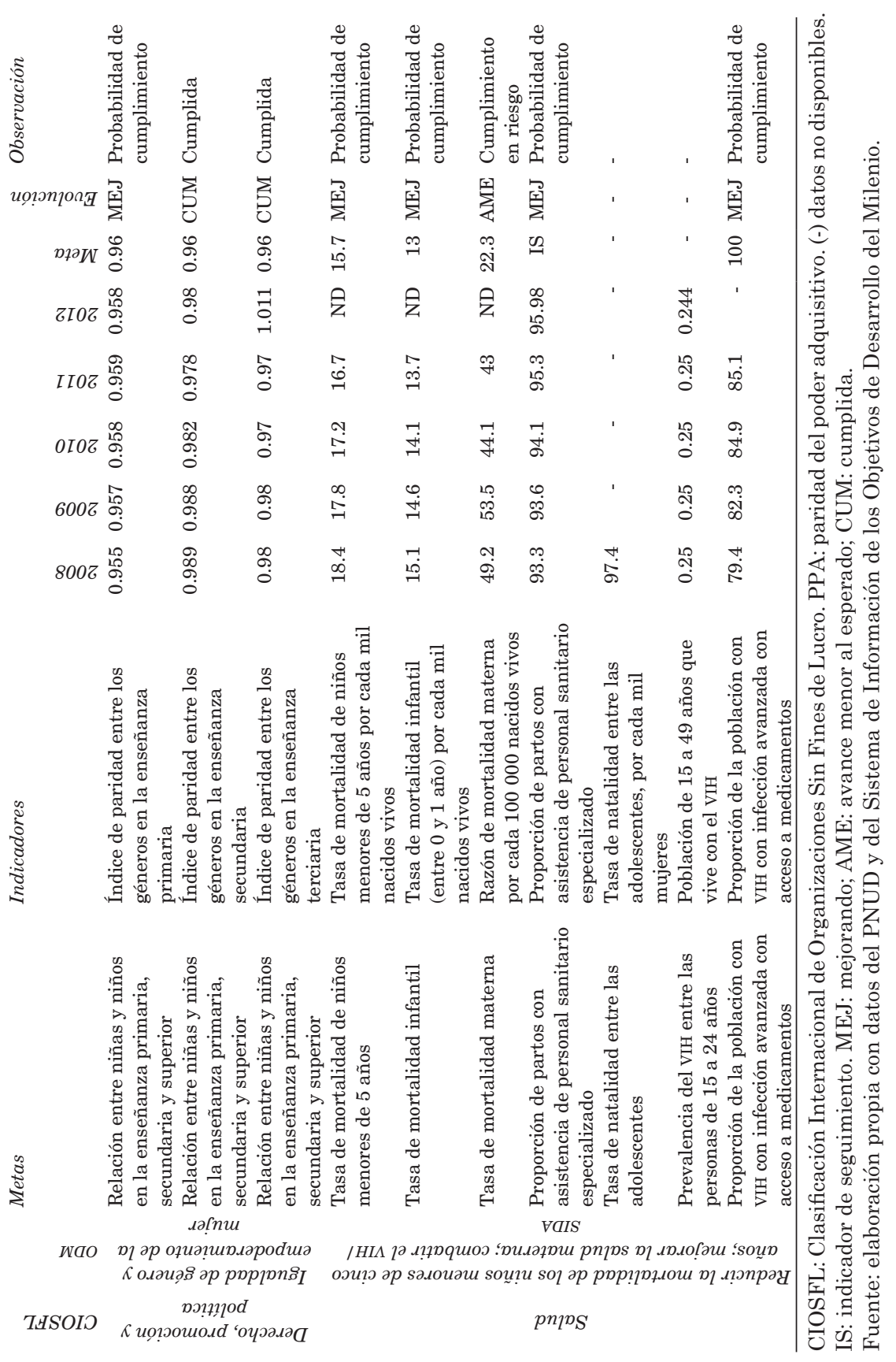

Sociedad $\&$ No. 60 
Omar Neme Castillo, Ana Lilia Valderrama Santibáñez y Álvaro Martín Vázquez Leyva

Cuadro 2. Apoyos destinados a OSC por la Administración Pública Federal, 2012 (miles de pesos)

\section{Unidad o Entidad}

Secretaría de Desarrollo Social (SEDESOL)

Instituto Nacional de Desarrollo Social

Dirección General de Opciones Productivas

Dirección General de Atención a Grupos Priori-

tarios

Secretaría de Educación Públicas (SEP)

Consejo Nacional para la Cultura y las Artes

Consejo Nacional de Cultura Física y Deporte

Instituto Mexicano de la Juventud

Instituto Nacional para la Educación de los Adultos

Secretaría de Economía (SE)

Dirección General de Comercio Interior y Economía Digital

Subsecretaría para la Pequeña y Mediana Empresa

Secretaría de Gobernación (SEGOB)

Comisión Nacional para Prevenir y Erradicar la

Violencia contra las Mujeres

Secretaría de Hacienda y Crédito Público (SHCP)

Financiera Rural

Comisión Nacional para el Desarrollo de los Pueblos Indígenas

Instituto Nacional de las Mujeres

Secretaría de Agricultura, Ganadería, Desarrollo

Rural, Pesca y Alimentación (SAGARPA)

Instituto Nacional para el Desarrollo de Capacidades del Sector Rural, A.C.

Secretaría de Salud (SSA)

Administración del Patriminio de la Beneficiencia

Pública

Centro Nacional para la Prevención y el Control del SIDA/VIH

Centro Nacional de Equidad de Género y Salud

Reproductiva

Sistema Nacional para el Desarrollo Integral de la Familia

Secretaría de Medio Ambiente y Recursos Naturales (SEMARNAT)

Centro de Educación y Capacitación para el Desarrollo Sustentable

Comisión Nacional Forestal

Comisión Nacional de Aguas Naturales Protegidas

Secretaría de Energía (SENER)

Petróleos Mexicanos

\begin{tabular}{rrr} 
Número & \multicolumn{1}{c}{ Monto } & Promedio \\
2,069 & $903,486.5$ & 436.7 \\
1,838 & $398,943.8$ & 217.1 \\
60 & $43,828.8$ & 730.5 \\
181 & $461,799.4$ & $2,551.4$ \\
& & \\
619 & $2,437,185.6$ & $3,937.3$ \\
291 & $911,919.6$ & $3,133.7$ \\
70 & $423,573.1$ & $6,051.0$ \\
115 & $45,624.1$ & 396.7 \\
63 & $807,078.4$ & $12,810.8$ \\
187 & $1,296,522.5$ & $6,933.3$ \\
66 & $295,253.8$ & $4,473.5$ \\
& & \\
79 & $767,518.6$ & $9,715.4$ \\
3 & 600.0 & 200.0 \\
3 & 600.0 & 200.0 \\
& & \\
1,823 & $473,181.1$ & 259.6 \\
1,349 & $333,018.6$ & 246.9 \\
421 & $121,660.7$ & 289.0 \\
& & \\
51 & $12,021.8$ & 235.7 \\
210 & $487,908.5$ & $2,323.4$ \\
& & \\
97 & $305,458.5$ & $3,149.1$ \\
& & \\
239 & $232,961.3$ & 974.7 \\
126 & $35,604.9$ & 282.6 \\
& & \\
28 & $24,702.1$ & 882.2 \\
& & \\
34 & $135,854.3$ & $3,995.7$ \\
& & \\
51 & $36,799.9$ & 721.6 \\
& & \\
243 & $107,337.8$ & 441.7 \\
& & \\
39 & $3,944.2$ & 101.1 \\
164 & $88,228.0$ & 538.0 \\
10 & $33,619.3$ & 301.6 \\
10 & $33,247.1$ & $3,324.7$ \\
$3,324.7$ \\
\hline 10
\end{tabular}

Fuente: elaboración propia con datos de la Cuenta de la Hacienda Pública 2012. 
intervenciones de las OSC, a partir de sus capacidades de incidencia, se presentan principalmente en este tipo de áreas, el impacto en las metas parece potenciarse. Al respecto, el número total de proyectos PCS creció 15\% de 2009 a 2012; mientras que el monto promedio otorgado pasó de 208.6 a 217000 pesos, un crecimiento de 4.1\%.

El cuadro 3 muestra la evolución del financiamiento PCS por categoría de la CIOSFL. ${ }^{17}$ En 2012, el número de proyectos y los montos se concentran en las categorías directamente asociadas con los ODM, esto es, desarrollo y vivienda, derecho, promoción y política, enseñanza e investigación y salud con más del 73\%. Durante todo el periodo, las categorías derecho, promoción y política, desarrollo y vivienda y cultura y recreación recibieron el mayor financiamiento promedio y registraron las mayores tasas de cambio. En consecuencia, parecería que la orientación de apoyos del PCS está en línea con al menos dos de los objetivos del milenio: con la igualdad de género y el empoderamiento de la mujer, y con la erradicación de la pobreza y el hambre; particularmente el último cae en las acciones de combate a la pobreza a través de la mejora de las condiciones físicas y sociales.

Desde este enfoque, las acciones de los actores sociales contribuyen no solo a los objetivos, sino a su institucionalización como agentes de cambio económico y social y, en última instancia, también sientan las bases para la trascendencia del tercer sector en el país.

Por otro lado, en todo el periodo se financiaron 3302 OSC en 6886 proyectos distribuidos en cuarenta convocatorias distintas, a nivel central y estatal. ${ }^{18}$ No obstante, el monto

17. La base de datos de OSC beneficiarias del PCS presentan información de los montos federales aportados por Indesol por tipo de convocatoria (véase Padrón de Beneficiarios PCS varios números). Estos datos se agruparon, considerando los objetivos de cada convocatoria y proyecto, de acuerdo a la categorización funcional de la Clasificación Internacional de Organizaciones Sin Fines de Lucro. 18. Se excluyeron veintiseis organizaciones que fueron apoyadas, pero que en el Padrón de Beneficiarios aún no se les asignaba monto económico para el apoyo. 
Omar Neme Castillo, Ana Lilia Valderrama Santibáñez y Álvaro Martín Vázquez Leyva

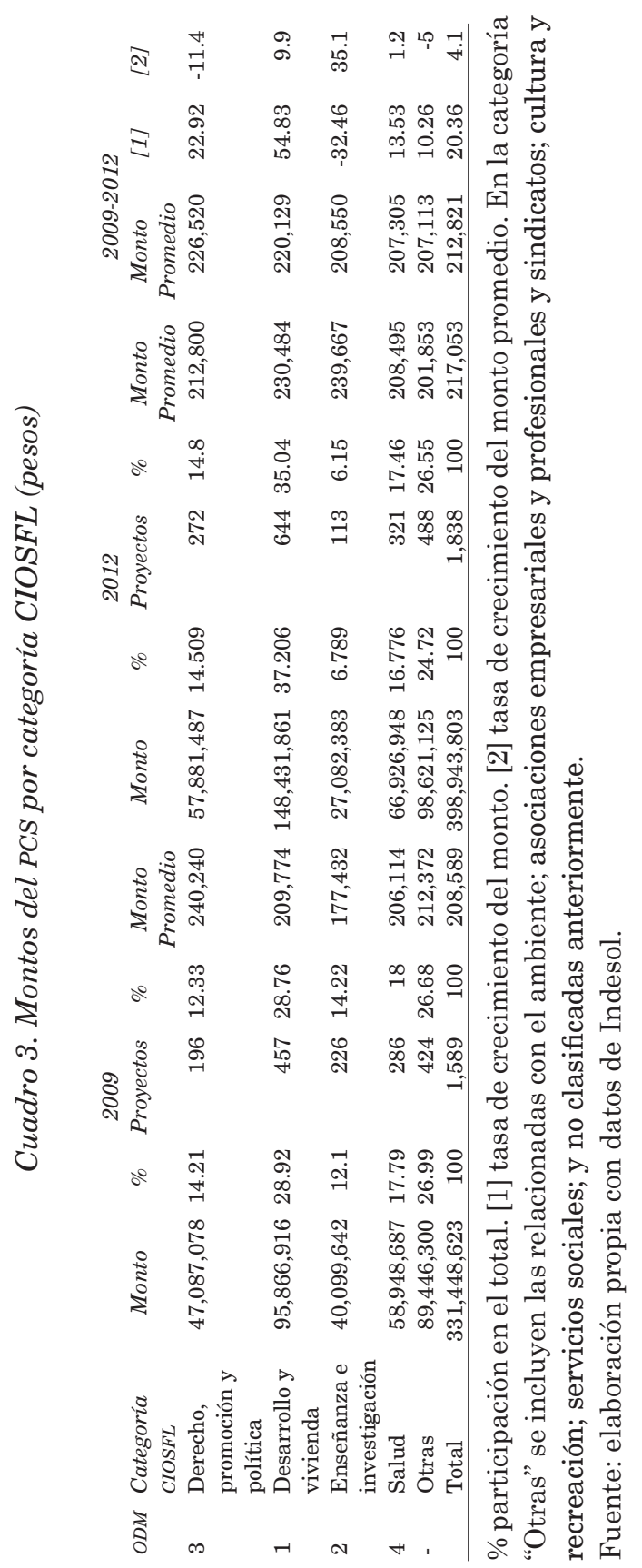


de los recursos públicos destinados a apoyar las acciones de los actores sociales no aumentó en la proporción que lo hicieron las OSC. En 2009 existían 8,916 OsC inscritas en Registro Federal de OsC, y en el 2012 el número creció $(19,826$, un aumento del 122\%). En contraste, los recursos económicos destinados a las OSC a través del PCS únicamente crecieron $20 \%$, verificándose así los resultados de evaluaciones externas al programa que señalan la limitación de los apoyos otorgados (Verduzco et ál., 2009).

En el cuadro 4 se muestran tanto las organizaciones que participaron en los cuatro años del periodo con al menos un proyecto como los proyectos recurrentes en al menos dos años del periodo. Se observa que el monto total de los apoyos económicos otorgados a este tipo de OSC representó 40\% del total del financiamiento del PCS en los años 2009 a 2012. Si se sigue el principio de eficiencia económica, esto implicaría que tal tipo de OSC es la de mayor contribución a los ODM. Las capacidades de estas organizaciones les permiten participar sistemáticamente en el programa; sin embargo, menos del $7 \%$ de las organizaciones en el PCS durante 2009 y hasta 2012 ejecutaron este tipo de proyectos (OSC recurrentes). ${ }^{19}$ Estas OSC participan con $17.4 \%$ de los proyectos PCS; cifra que sugiere un grado de concentración de los recursos toda vez que reciben en promedio 22500 pesos más que las OSC no "recurrentes". Esta situación refleja esfuerzos gubernamentales por asignar recursos eficientemente a organizaciones con programas en áreas de mayor relevancia para los ODM. ${ }^{20}$

19. De acuerdo con datos del Indesol, durante el periodo 2009-2012 un total de 3539 OSC accedieron a recursos del programa de coinversión, de las cuales $56.9 \%$ participó con proyectos en un solo año; $23 \%$ con proyectos en dos años; $13.6 \%$ en tres años y únicamente $6.5 \%$ de las organizaciones implementaron proyectos en los cuatro años.

20. Para Valderrama et ál. (20I3) existen dos características distintivas de este tipo de OSC. La primera, es que en promedio tienen una edad de 19.8 años, implicando cierto grado de profesionalización e institucionalización y la segunda es que hacen uso de herramientas de las tecnologías de la información y comunicación 
Omar Neme Castillo, Ana Lilia Valderrama Santibáñez y Álvaro Martín Vázquez Leyva

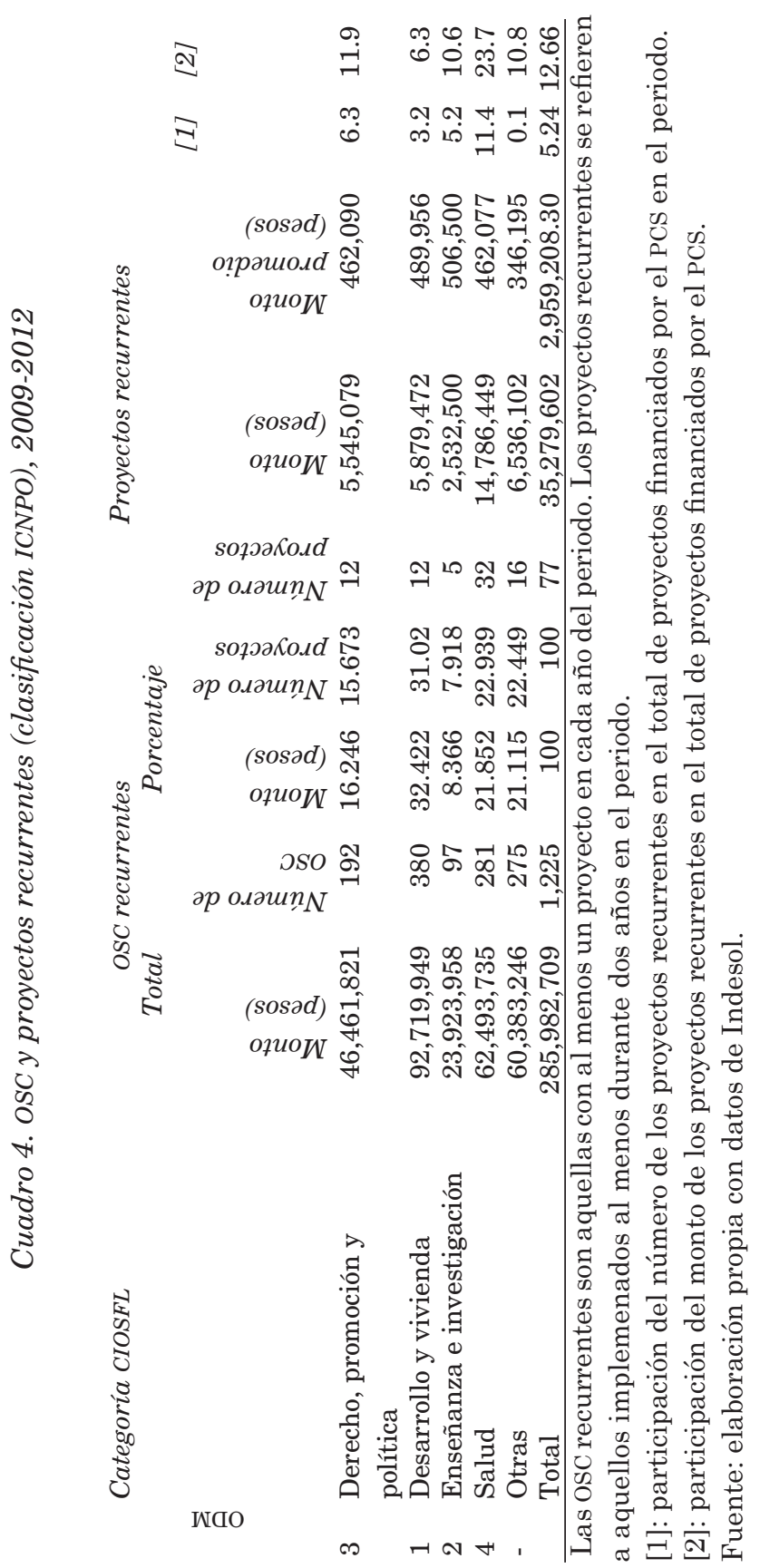


Considerando los proyectos de las osC recurrentes, se aprecia que solo $6.3 \%$ de los proyectos se repite. El monto de los recursos asignados a proyectos recurrentes representa $12.3 \%$ del total financiado a este grupo. El monto de los proyectos que se ejecutan más de una vez es el doble del monto promedio del total de proyectos. Centrándose en las categorías, se observa que la mayor continuidad de proyectos se presenta en salud, seguidos por los proyectos en servicios sociales. Aún más: en salud prácticamente una quinta parte de los montos se emplea en proyectos de continuidad. Esta situación contrasta con el hecho de que en los ODM asociados a salud aún no se alcanza ninguna meta e incluso hay una meta con riesgo de incumplimiento. En corto, la meta es reducir en 2015 la mortalidad materna en tres cuartas partes -lo cual implica una tasa de mortalidad materna de 22.3-, pero considérese que en 2011 dicha tasa se encontraba en niveles muy elevados: 43 muertes por cada 100000 nacidos vivos. Es importante precisar que este aspecto es atendido directamente por los proyectos de las OSC.

Enfocando los objetivos del milenio, en la gráfica 1 se observa que los proyectos PCS no relacionados directamente con las metas son los de mayor recurrencia en todo el periodo, seguidos por aquellos vinculados a la erradicación de la pobreza y hambre, y la salud. Los proyectos asociados con la enseñanza primaria universal -que se repiten en al menos dos años de la muestra-son los de menor replicabilidad. Pero el $62 \%$ de los proyectos recurrentes se asocian directamente con los cuatro ODM considerados.

En este sentido, en el cuadro 5 se muestran los coeficientes de correlación entre indicadores seleccionados de los objetivos del milenio y los proyectos PCS recurrentes medidos

para difundir actividades y resultados, hacerse llegar de voluntarios y recursos y acercarse con beneficiarios. 


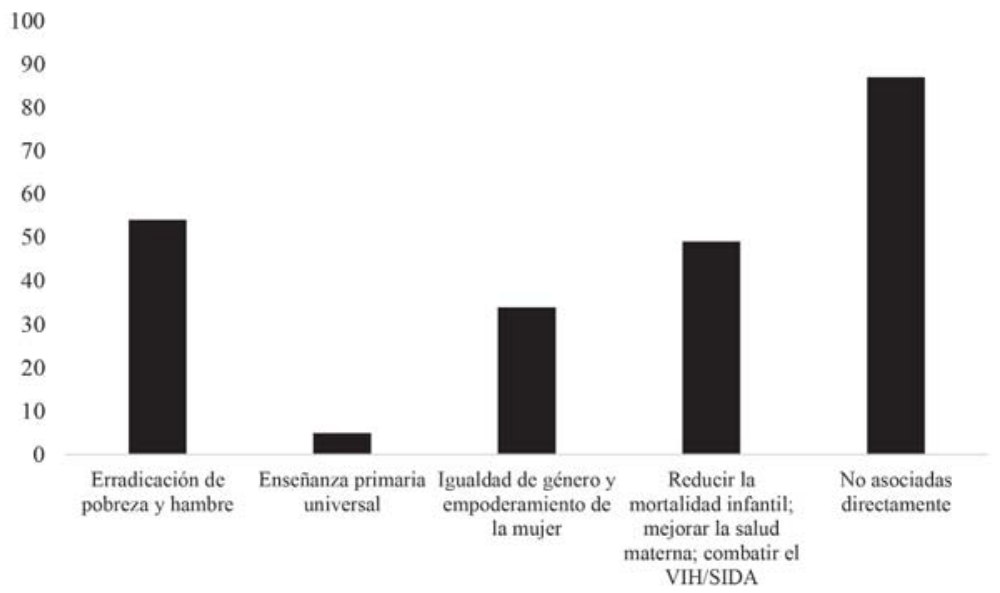

por el número de proyectos o por el apoyo económico asignado a ellos. ${ }^{21}$ En general, se aprecia una baja correlación entre proyectos recurrentes y avances en los indicadores, con excepciones para los tres primeros objetivos. Considerando primero el número de proyectos, se tiene que seis indicadores ODM se asocian positivamente con proyectos recurrentes. Cuando crece el número de proyectos el empleo aumenta, se incrementan el número de personas trabajando por cuenta propia, hay mayor acceso al agua potable, la matrícula de la enseñanza primaria crece, la deserción disminuye, y hay menor desigualdad entre niños y niñas.

21 . Se realiza un análisis de correlación; lo que permite determinar el coeficiente de correlación simple entre los proyectos PCS recurrentes, ya sea en número o monto, y los cuatro objetivos del milenio para los que hay información disponible para todas las series. El coeficiente varía entre - I, implicando una correlación perfecta y negativa $y+I$, que señala una correlación perfecta y positiva. Un coeficiente cercano a cero indicaría ausencia de asociación lineal entre estas variables cuantitativas. Se emplea el coeficiente de correlación de Pearson que se define: $\mathrm{e}=\Sigma x_{i} y_{i}-\left(n \dot{x} \dot{y} / n S_{x} S_{y}\right)$, donde el numerador es la covarianza y $S x$ y $S y$ son, respectivamente, las desviaciones estándar de $X$ y $Y$. 
Cuadro 5. Indicadores de los ODM y proyectos PCS recurrentes: correlación

\begin{tabular}{|c|c|c|c|}
\hline \multirow[t]{3}{*}{ Objetivos } & \multirow[t]{3}{*}{ Indicador } & \multicolumn{2}{|c|}{$\begin{array}{l}\text { Coeficiente de } \\
\text { correlación }\end{array}$} \\
\hline & & $\begin{array}{l}\text { Número de } \\
\text { proyectos }\end{array}$ & $\begin{array}{l}\text { Monto } \\
\text { de los } \\
\text { provectos }\end{array}$ \\
\hline & & recarrenues & recurrentes \\
\hline $\begin{array}{l}\text { Erradicación } \\
\text { de pobreza y }\end{array}$ & $\begin{array}{l}\text { Tasa de crecimiento del PIB por persona } \\
\text { empleada }\end{array}$ & -0.130 & 0.266 \\
\hline & Razón empleo/población & 0.019 & -0.256 \\
\hline & $\begin{array}{l}\text { Proporción de la población ocupada que } \\
\text { trabaja por cuenta propia o en negocios } \\
\text { familiares }\end{array}$ & 0.806 & -0.952 \\
\hline & Población desnutrida & 0.142 & 0.049 \\
\hline & $\begin{array}{l}\text { Proporción de la población ocupada } \\
\text { con acceso a fuentes mejoradas de }\end{array}$ & 0.021 & -0.049 \\
\hline $\begin{array}{l}\text { Enseñanza } \\
\text { primaria }\end{array}$ & $\begin{array}{l}\text { abastecimiento de agua potable } \\
\text { Tasa de matriculación en la enseñanza } \\
\text { primaria }\end{array}$ & 0.445 & -0.611 \\
\hline universal & $\begin{array}{l}\text { Porcentaje de alumnos que comienzan } \\
\text { el primer grado y llegan al último grado }\end{array}$ & 0.19 & -0.221 \\
\hline & $\begin{array}{l}\text { Tasa de alfabetización de las personas } \\
\text { de } 15 \text { a } 24 \text { años }\end{array}$ & -0.208 & -0.104 \\
\hline Igualdad & Índice de paridad entre los géneros en & 0.324 & -0.638 \\
\hline de género y & la enseñanza primaria & & \\
\hline empoderamiento & Índice de paridad entre los géneros en & -0.368 & 0.412 \\
\hline de la mujer & $\begin{array}{l}\text { la enseñanza secundaria } \\
\text { Índice de paridad entre los géneros en } \\
\text { la enseñanza terciaria }\end{array}$ & -0.310 & 0.433 \\
\hline $\begin{array}{l}\text { Reducir la } \\
\text { mortalidad } \\
\text { infantil; } \\
\text { mejorar la } \\
\text { salud materna; } \\
\text { combatir el vIH/ } \\
\text { SIDA }\end{array}$ & $\begin{array}{l}\text { Proporción de partos con asistencia de } \\
\text { personal sanitario especializado }\end{array}$ & -0.035 & -0.219 \\
\hline
\end{tabular}

Fuente: elaboración propia. 
Lo expuesto puede explicarse dada la naturaleza de los proyectos. Muchos de ellos ofrecen talleres de capacitación y desarrollo de habilidades productivas a nivel individual y comunitario, permitiendo mayores oportunidades de ingreso al mercado laboral o bien el establecimiento de pequeñas empresas locales. Además, en el ámbito del derecho, promoción y política existen diversos proyectos que promueven la igualdad de género en las escuelas primarias y secundarias. Si bien los proyectos PCS que ofrecen facilidades para la educación primaria y secundaria son reducidos, el efecto positivo en este renglón podría alcanzarse dado el mayor ingreso familiar derivado de la capacitación laboral promovida por estas organizaciones.

Por el contrario, seis indicadores muestran correlación negativa con este tipo de proyectos. Por ejemplo, el mayor número de proyectos explica una reducción de la tasa de crecimiento del PIB por empleado, un aumento de la población desnutrida, una menor tasa de alfabetización, mayor desigualdad de género en la enseñanza secundaria y terciaria, y una menor proporción de partos con personal especializado. Una de las posibles explicaciones de esta situación negativa es que los proyectos recurrentes llevan a una menor productividad, dado que aumenta el número de trabajadores potenciales $\mathrm{y}$, por ende, decrece el PIB por trabajador; o bien, considerando las condiciones socioeconómicas, la intervención de las OSC con proyectos productivos y capacitación genera establecimientos con empleos informales y una inserción laboral que implica el abandono de los estudios. Además, el aumento de la desnutrición en zonas marginadas reflejaría la ineficiencia de los proyectos que atienden esta problemática, quizá por seguir un enfoque demasiado asistencialista, que los hace insostenibles o evita que la comunidad se los apropie. No obstante, la correlación señala también que el aumento de 
la desnutrición y la desigualdad en las escuelas secundaria y terciaria, el menor avance del PIB por trabajador, de la alfabetización y de la atención especializada a partos lleva a la urgente necesidad de incrementar el número de proyectos de coinversión mediante los programas de continuidad que establecen las OSC.

Al centrarse en la correlación entre indicadores ODM y el monto de los proyectos de coinversión recurrentes, la situación de las organizaciones y del propio programa de coinversión es marcadamente negativa. Solo tres indicadores se asocian positivamente con mayores montos de coinversión, esto es, el crecimiento del PIB per worker y la equidad de género en la enseñanza secundaria y terciaria; dos renglones que las organizaciones solo atienden de forma indirecta o marginal. Desde esta perspectiva, y contrario a lo esperado, se visualiza una característica de regresividad de los proyectos de coinversión recurrentes. En otras palabras, el mayor financiamiento a recurrentes limita el avance de los indicadores hacia las metas asociadas a personas en condiciones de vulnerabilidad.

\section{Reflexiones finales}

Los proyectos recurrentes contribuyen a focalizar esfuerzos propiciando un mayor grado de especialización y atención a problemas sociales, por lo que su contribución a los ODM es potencialmente alta. En este sentido, en el marco del PND, parece que el Estado se complementa con las OSC, quienes a través de la implementación de distintos proyectos atienden problemáticas muy puntuales.

Los resultados encontrados en este artículo son de carácter indicativo y no conclusivo, puesto que para lograr lo segundo el análisis debería incluir todas las organizaciones de la sociedad civil, esto es, tanto recurrentes como no recurrentes. No obstante, si bien seis de cada diez pro- 
yectos de coinversión recurrentes se orientan a problemas vinculados con los objetivos del milenio, no parece existir una clara contribución de estos. Si bien existen otros mecanismos de participación de las OSC en estos temas -como los convenios de colaboración Federales para prevenir y atender el trabajo infantil o el Programa de Atención a Personas con Discapacidad-, donde las organizaciones ejecutan proyectos productivos para estas personas, los cuales podrían impactar en los indicadores del milenio a través de un camino más corto, esta potencial contribución se da fuera del contexto de proyectos de coinversión recurrentes. Por ejemplo, la Secretaría de Salud, a través del CENSIDA financia proyectos de OSC de prevención focalizada de VIH en grupos de mayor riesgo; medida que puede contribuir directamente a la meta asociada al indicador "población de 15 a 49 años que vive con VIH". Sin embargo, el aporte de los proyectos PCS recurrentes al desarrollo social (ODM) parece circunscribirse a la generación de capacidades productivas en los individuos, principalmente en grupos vulnerables. Así, conforme estos individuos cubran ciertas necesidades por la implementación de proyectos de coinversión, tendrán mayores capacidades productivas.

Además de lo señalado, y desde un enfoque cualitativo que permite contextualizar el alcance de las organizaciones de la sociedad civil, parece que los proyectos PCS recurrentes se orientan más hacia la construcción de libertades positivas, puesto que contribuyen a la capacidad efectiva de los usuarios para "hacer algo" productivamente, es decir, valerse por ellos mismos. Pese a ello, conviene señalar que la elevada incidencia social de estos proyectos también podría contribuir a la libertad negativa, dado que implica una elección del proyecto a ejecutar que se realiza conjuntamente entre las OSC y la comunidad.

De la misma manera, los proyectos PCS recurrentes se relacionan con la igualdad de oportunidades al implementar 
acciones que llevan no a un aumento en los bienes materiales, sino a un aumento en las oportunidades funcionales y en las capacidades de desarrollo derivado del servicio brindado o generado por estos proyectos. En consecuencia, este tipo de organizaciones y proyectos contribuyen al desarrollo social desde el enfoque de capacidades $\mathrm{y}$, por lo tanto, cabe esperar un efecto en los ODM en un horizonte mayor. Con todo $-\mathrm{y}$ a pesar del incremento de apoyos económicos del PCS-, las demandas sociales, de acuerdo con los indicadores del milenio, no se han reducido en igual proporción, especialmente aquellas vinculadas con la salud y con la erradicación de la pobreza y el hambre. Por consiguiente, los nuevos proyectos de coinversión podrían reorientarse o centrarse en estas dimensiones del desarrollo social.

Ante tal panorama puede concluirse que la contribución directa del Programa de Coinversión Social y de las Organizaciones de la Sociedad Civil-y sus proyectos recurrentes-a los objetivos del milenio ha sido limitada. No obstante, la Declaración y Objetivos del Milenio representan una estructura lógica aceptada mundialmente para la implementación de diversas iniciativas. Es responsabilidad tanto de los gobiernos nacionales y subnacionales como de las organizaciones de la sociedad civil apropiarse de estos objetivos. Por lo dicho, las OSC estudiadas deberían revisar y priorizar sus planes, proyectos, objetivos, estrategias e indicadores a la luz de los ODM. El gobierno no puede alcanzar las metas fijadas y futuras por sí mismo. Los objetivos sin duda son desafiantes y requieren de inversiones sostenidas y orientadas estratégicamente, recursos humanos y técnicos, así como estrategias y acciones coordinadas para incrementar la eficiencia de las acciones de los actores sociales.

En palabras de los expertos, si bien los ODM son viables técnica y económicamente (y por eso contribuyen al combate de los problemas del desarrollo), estos enfrentan una dificultad asociada con la voluntad política, lo cual se traduce 
Omar Neme Castillo, Ana Lilia Valderrama Santibáñez y Álvaro Martín Vázquez Leyva

en la débil apropiación que de ellos hacen las naciones, y se observa en la implementación de estrategias para contribuir a las metas por parte de los actores principales. Por ende, el gobierno debería incentivar a las OsC a formular y ejecutar proyectos para alcanzar los ODM. Y en este orden de ideas, el marco regulatorio del Indesol debería incluir una renovación estratégica de financiamientos basados en las contribuciones dichas metas para un uso eficaz de los recursos públicos.

Fecha de recepción: 08 de enero de 2014

Bibliografía

Alonso, L., 1999, "La juventud en el tercer sector: redefinición del bienestar, redefinición de la ciudadanía", Estudios de Juventud, vol. 45-99, pp. 9-20.

Amin, S., 2006, "The Millennium Development Goals: A critique from the South", Monthly Review, vol. 57-10, PP. I-I5.

Atisophon, V., J. Bueren, G. De Paepe, C. Garroway, y J. Stijns, 20II, "Revisiting MDG cost estimates from a domestic resource mobilisation perspective", $O E C D$ Working Paper, núm. 306.

Banco Interamericano de Desarrollo, 2004, "Los Objetivos de Desarrollo del Milenio en América Latina y El Caribe. Retos, acciones y compromisos", Washington, Estados Unidos, en línea: http://www.eclac.cl/mdg/docs/ IADBPublicDoc.pdf

Bresser, L., y Cunill, N., 1998, Lo público no estatal en la reforma del Estado, CLAD/Paidós, Argentina.

Canudas, R., 2012, "Planes Nacionales, Estrategias de Reducción de la Pobreza y ODM", Banco Inter-Americano de Desarrollo/Instituto Interamericano para el Desarrollo Económico y Social, en línea: http://www.iadb.org/es/ indes/indicadores-para-el-desarrollo,5876.html 
Centro Mexicano para la Filantropía, 20 I3, La acción solidaria de los mexicanos: Una aproximación, CEMEFI/Indesol, México, en línea: http://www.cemefi.org/servicios/ biblioteca-cif/lecturas-filantropicas.html

Centro de Estudios Sociales y de Opinión Pública Desarrollo Social, en línea: www.diputados.gob.mx/cesop/

Clark, J., 1997, "The State, popular participation and the voluntary sector", en D. Hulme y M. Edwards (eds.), NGOs, states and donors: Too close for comfort?, St. Martin's Press, Nueva York.

Coleman, J., 1997, "Social capital in the creation of human capital”, en A. Halsey, H. Lauder, P. Brown y A. Wells (eds.), Education: Culture, economy, society, Oxford University Press, Oxford.

Comisión Económica para América Latina, 2013, Elementos Básicos del Desarrollo Local y Regional, versión XI, Comisión Económica para América Latina e Instituto latinoamericano y del Caribe de Planificación Económica y Social, en línea: http://www.eclac.org/cgi-bin/getprod. asp?xml=/ilpes/capacitacion/8/48868/P48868.xml\&xsl=/ ilpes/tpl/p I5f.xsl\&base=/ilpes/tpl/top-bottom.xs|

Comisión Económica para América Latina, Sede subregional en México, en línea: http://www.eclac.org/mexico/ dsocial/

Cumbre Mundial de Desarrollo Social de las Naciones Unidas, 2000, en línea: http://www.un.org/es/millenniumgoals/news.shtml

Cumbre Mundial de Desarrollo Social de las Naciones Unidas 2010, en línea: http://www.un.org/es/millenniumgoals/news.shtml

Deepak, N., 201 I, “The MDGs beyond 2015”, Research Paper, núm. 38, Geneva.

Espadas, M., 2006, "El Tercer Sector construyendo ciudadanía: La participación del Tercer Sector en los servicios sociales en Andalucía", tesis de doctorado 
Omar Neme Castillo, Ana Lilia Valderrama Santibáñez y Álvaro Martín Vázquez Leyva

Bibliografía

en Sociología, Universidad Complutense de Madrid, en línea: http://biblioteca.ucm.es/tesis/cps/ucm-t29504.pdf Häuberer, J., 20I I, Social capital theory, Springer VS, p. 330. Holmes, R., Jones, N., y Espey, J., 2010, "The MDGs and gender”, ODI Policy Brief, June, Overseas Development Institute.

Hulme, D., 2010, "Lessons from the making of the MDGs: Human development meets results-based management in an unfair world”, IDS Bulletin, No. 4I-I, PP. I5-25.

Jahan, S., 20I0, “The MDGs beyond 20I5", IDS Bulletin, vol. $4 I-I$, Pp. 5 I-59.

Jolly, R., 2003, “Global Goals: The UN experience”, Human Development Report, UNDP.

Keeley, B., 2007, Human capital: How what you know shapes your life, OCDE Insights, Paris.

Khoo, S., 2005, "The Millennium Development Goals: A critical discussion”, Trocaire Development Review, pp. 43-56.

Langford, M., 2010, "A poverty of rights: Six ways to fix the MDGs”, IDS Bulletin, vol. 4I-I, pp. 83-9I.

Ley general de desarrollo social, recuperada de: http://www. diputados.gob.mx/LeyesBiblio/pdf/264.pdf

Manual sobre las Instituciones Sin Fines de Lucro en el Sistema de Cuentas Nacionales 2007. Naciones Unidas y Universidad Johns Hopkins.

Marshall, T., 1998, “Ciudadanía y clase social”, en Marshall, T. y Bottomore, T. (Eds.), Ciudadanía y clase social, Alianza Editorial, Madrid.

Midgley, J., 1995, Social development: The developmental perspective in social welfare. Thousand Oaks, CA: Sage Publications.

Moss, T., 2010, "What next for the Millennium Development Goals?", Global Policy, vol. I-2, pp. 218-220.

Najam, A., 1999, "Citizen organizations as policy entrepreneurs", en Lewis, D. (Ed.), International perspectives 
in voluntary action: reshaping the Third Sector, London: Earthscan.

Narayan, D., y Shah, T., 2000, "Connecting the local to the global: Voices of the poor", World Bank, Washington, D.C., en línea: http://siteresources.worldbank.org/INTPOVERTY/Resources/335642-II24II5I02975/I555I99-II2474I3784I0/ dec00_narsha.pdf

Olvera, A., 1998, Problemas conceptuales en el estudio de las organizaciones civiles: de la Sociedad Civil al Tercer Sector, Instituto de Investigaciones Histórico-Sociales, Universidad Veracruzana.

Ortega, E., P. Güell, N, Lechner, R. Vásquez, 2000, Desarrollo humano en Chile: Más sociedad para gobernar el futuro, Organización de las Naciones Unidas, en línea: http:// www.desarrollohumano.cl/archivos/principio.pdf

Pennant, R., 2005, Diversity, trust and community participation in England, Home Office Findings, núm. 253, Research, Development and Statistics Directorate, Londres.

PNUD, 2005, "Civil society contribution towards achieving the MDGs In The Gambia, Programa de las Naciones Unidas para el Desarrollo, ONU, Estados Unidos. ,2004, "Civil society perspectives on the Millenium Development Goals", Programa de las Naciones Unidas para el Desarrollo, Estados Unidos.

Putnam, R., 1995, “Bowling alone: America's declining social capital”, Journal of Democracy, vol. 6-I, pp. 65-78.

Putnam, R., y D. Goss, 2003, El declive del capital social, Galaxia Gutenberg, Barcelona.

Rodríguez, J., 2005, “Tercer sector: Una aproximación al debate sobre el término", Revista de Ciencias Sociales, vol. II-3, Pp. 26-4I.
Bibliografía 
Omar Neme Castillo, Ana Lilia Valderrama Santibáñez y Álvaro Martín Vázquez Leyva

Bibliografía

Salamon, L., 2008, The New Zealand non-profit sector in comparative perspective, Wellington: Office for the Community \& Voluntary Sector, New Zealand.

Salamon, L. y H. Anheier, 1999, The emerging sector revisited: A summary, revised estimates, Center for Civil Society Studies, Estados Unidos.

, 1994, The emerging sector. The Non-profit Sector in comparative perspective: An overview, Institute for Policy Studies, The Johns Hopkins University, Baltimore. SEDESOL, 2007, Programa Sectorial de Desarrollo Social $2007-$ 2012, Secretaría de Desarrollo Social, México.

Sen, A., 2000, "Consequential evaluation and practical reason”, Journal of Philosophy, vol. 97-9, pp. 477-502. , 1987, "Equality of what?", en J. Rawls y S. McMurrin (eds.), Liberty, equality and law: Selected tanner lectures on moral philosophy, University of UTAH Press. 1985, "The moral standing of the market", Social Philosophy and Policy, vol. 2-2, PP. I-28. , 1982, "Rights and agency", Philosophy and Public Affairs, vol. II-I, pp. 3-39.

Sermeño, A., 200I, "La sociedad civil. De la teoría a la realidad”, Sociológica, vol. 16-45, pp. 459-464.

Shepherd, A., 2008, "Achieving the MDGs: The fundamentals”, ODI Briefing Paper, núm. 43, Overseas Development Institute, Londres.

Sumner, A., 2009, "Rethinking development policy: Beyond 20I5”, The Broker, vol. I4, pp. 8-I3.

Thayer, L. y A. Elizalde, 20II, "La dimensión de lo público. Sociedad civil y Estado", Polis Revista de la Universidad Bolivariana, vol. 10-30, pp. 7-I5.

Vandemoortele, J., 2009, "The MDGs conundrum: Missing the targets without missing the point", Development Policy Review, vol. 27-4, pp. 355-37I. 
Organizaciones de la Sociedad Civil y Objetivos de Desarrollo del Milenio:

el caso del PCS

Vandemoortele, J., y E. Delamonica, 20 I0, "Taking the MDGs beyond 20I5: Hasten slowly”, IDS Bulletin, núm. 4I-I, pp. 60-69.

Valderrama, A., R. Fernández, M. Vázquez y O. Neme, 20I3, "Capacidad de incidencia de las Organizaciones de la Sociedad Civil: El caso de los Proyectos de Coinversión Social”, Mimeo.

Verduzco, G., 200I, "La evolución del tercer sector en México y el problema de su significado en la relación entre lo público y lo privado", Estudios Sociológicos, vol. 19-I, pp. 27-48.

Verduzco, M., J. Trujillo y M. Tapia, 2009, Fondos públicos para organizaciones de la sociedad civil, Análisis del programa de coinversión social, Alternativas y Capacidades A.C., México. 